\title{
Exploring the Use of Montage in Chinese Films
}

\author{
Shiya $\mathrm{xu}$ \\ Xiamen Fujian Xiamen University Tan Tah Kee College, China \\ Corresponding author's e-mail: angela@cas-harbour.org
}

\begin{abstract}
Montage is one of the key elements in determining the art of film, which plays an irreplaceable role in the film. In attracting the audience, shaping the characters, the construction of the story also plays a key role. For the art of film, whether artistic or technical, montage is very important. How the montage will put to use in Chinese films is the starting point and the focus of this thesis, and will be used as an example from three films to tell the key role of narrative montage in Chinese films.
\end{abstract}

Key words: Chinese film, Post-production, Editing art, Montage

\section{INTRODUCTION}

Looking around the world today, cultural industry has become an important strategic industry. In China the cultural industry has become a pillar industry of the national economy, increasing the support of excellent cultural products. The film industry serves as an important part to stimulate the development and consumption of the field of cultural products. The montage of Chinese films is also particularly important. Montage combines pictures and sounds to form a language system of film and television, such a simple picture language is given a new meaning, everyone for such a picture sound combination understanding also has a different understanding, contributing to the film this art[1]. Montage in the film is mainly narrative and expressing an image two roles, the main purpose of the two narrative montage is to tell the plot, show the story, the audience into the storyline. As a comprehensive art form, the film has extensively absorbed the elements of traditional art such as literature, comedy, painting, music, and has formed a new art form of film. Therefore, as an editor, it is necessary to use a certain aesthetic sense, literary cultivation, and artistic cells, in order to better grasp the film's light, shadow, color, background music and the rhythm of the editing, thus completing a good film work. But since the film was born, there is no concept of editing. There is also no concept of montage. This article analyzes the use and development of narrative montage in Chinese films from the perspective of several Chinese films.

\section{THE ORIGIN AND FUNCTION OF MONTAGE}

The word montage comes from French and means "splicing", but in Russia it was developed into a theory of lens combinations in movies. When different lenses are spliced together, it often produces a specific meaning that each lens does not have when it exists alone. The birth of the montage came from an accident. Montage is based on what the film needs to express, and the psychological order of the audience, divides a movie into many shots, and then arranges them into new movie clips. To put it simply, it is the way to separate the shots into new movie clips. First of all, it is a means of camera shooting, and then the means of editing. Sergei M. Eisenstein's famous saying about montage theory: "The queue of two montages is not the sum of two numbers, but the product of two numbers." The famous "Kuleshov effect" is a powerful argument of Eisenstein[1]. Evidently, by this means, the narrative of the film is greatly free in the use of time and space, and through the juxtaposition and crossover of the movements of two different spaces, it can create a tense atmosphere, or between the characters in the two places. Relationship. Montage is not simply editing and combining the lenses, but reflecting the inner truth. The famous Russian director Pudovkin once said: "The basis of film art is montage." Montage's role in the film cannot be underestimated[2]. Montage's technique runs through the beginning and end of film art [1]. Although film time and space is a montage of fictional scenes, in the process of film composition, through the use of different montage techniques, or flashbacks, or crossovers, or metaphors, the film art shows a richer aesthetic [2]. The effect is to create a more beautiful film time and space than reality.

\section{THE USE OF MONTAGE IN CROUCHING TIGER, HIDDEN DRAGON}

"Crouching Tiger, Hidden Dragon" is a martial arts action film directed by Ang Lee. It mainly tells about the resentment of the rivers and lakes that emerged after the hero Li Mubai was ready to withdraw from the rivers and lakes. In the entire movie "Crouching Tiger, Hidden Dragon", the martial arts scene takes up a lot of space. First of all, the first wonderful martial arts scene is $\mathrm{Yu}$ Xiulian chasing the thief who steals the sword. In this scene, Ang Lee arranged montage editing, fast-paced editing and wonderful martial arts scenes, and brought the audience into the exciting emotional atmosphere of the story. In the fight scene a large number of the use of sound 
montage, the use of flute such as the representative of Chinese elements, violin and string lining, with the voice of the flute as the main melody to promote the storyline, the audience's heart is tightly affected. Such sound effects can be very good baking atmosphere, to create the ideal sense of film rhythm.In the second half of the film, the most exciting and impressive are the fragments of $\mathrm{Li}$ Mubai and Yu Yulong in the bamboo forest.In Li Mubai to accept Yujiaolong as an apprentice, Li taught Jade heart sex fragments, the use of the far lens stressed the two characters in the huge bamboo forest in the small, but also showed the two characters of martial arts excellently. In the process of chasing bamboo forest, the lens constantly adjusts with the mood of two people. The lens is also transferred from the sword of two people to the facial expressions of two people, so that the viewer's vision always follows the changes of the lens, constantly changing the emotions of the characters and feeling the current intense and exciting atmosphere. Beautiful martial arts scene, conversion of light and sword scenes, beautiful Chinese elements. Unlike other martial arts movies, this movie has no bloody killings and killings. Instead, it is light, beautiful, and poetic. The battle scene is also very beautiful. Director Ang Lee skillfully uses the lens to show the connection between time and space, and uses lens and stitching techniques to express the sense of speed and rhythm. Such a clip motivates the audience was moved by the tension and excitement, making the audience more immersed in the plot.In this movie, Ang Lee used a lot of beautiful shots and beautiful soundtracks to make this film a classic in the history of film.

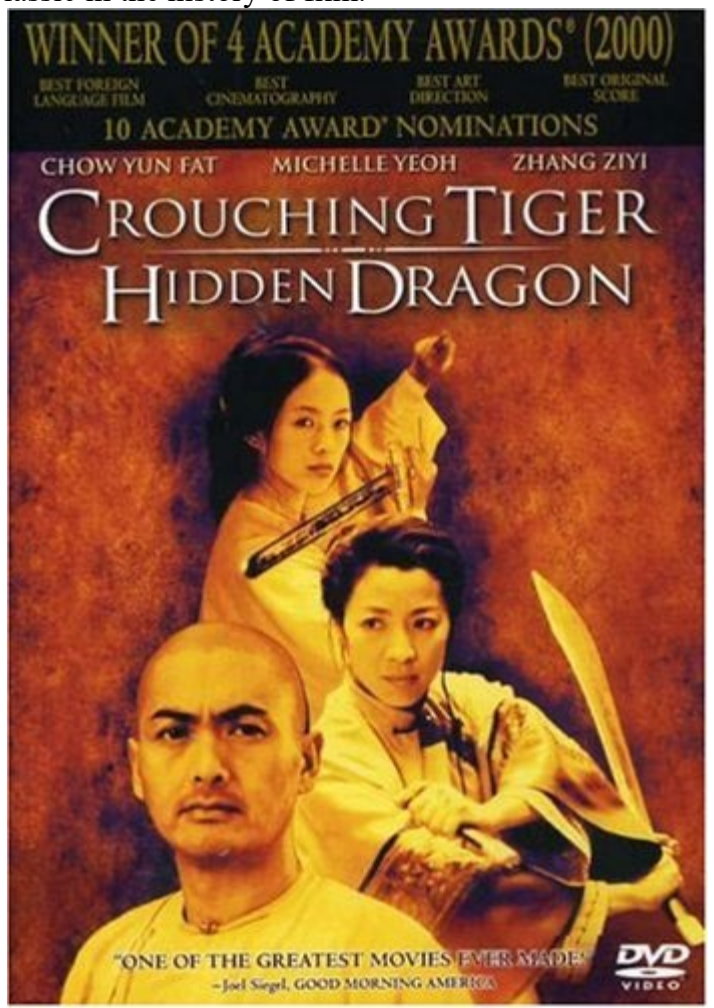

Figure 1. Poster of the Film Crouching Tiger HIdden Dragon [3].

\section{THE USE OF MONTAGE IN FAREWELL MY CONCUBINE}

"Farewell My Concubine" is a Peking Opera directed by Chen Kaige. It is said that Duan Xiaolou and Cheng Dieyi are brothers respectively. They are male characters and female characters. When the small stage of the latter stage becomes famous, he will marry the famous prostitute, Juxian, and the love and hate that arise between the three. The opening of the movie is the childhood bean. the play, which broke bean's finger, used a very beautiful voice montage. Yanhong pull hurriedly out of the bean, heavy drum mingling sound feel very depressed and suffocating. At the same time the sound of pigeon whistles from weak to strong, then weak, and then disappear. The sound disappears when Yanhong picks up the knife, and the clip goes to the apprentice, making it easy for even the audience to guess what's going to happen. Bean's fingers were cut off, and the sound was all that was left to his screams, drums and pigeon whistles ringing again. This whole play, interspersed with many sounds, and the sound constantly change strong and weak, rhythmic, with the picture will bring the audience into the story, feel as if they have been cut off the general heart and pain, while such a sound picture also hints at the fate of the characters, promotes the storyline. It is a very beautiful use of a montage. There is a scene where the beans try to escape the troupe. He longs for the world outside. Pushing the door open, the kite is facing him. Spiritual montages are used here. By opening the door by the beans, the people outside the door holding a kite, symbolizing the freedom of the kite. This fragment shows that the bean is mentally eager to be free, then from childhood to adolescence to adulthood, the film uses continuous montage, press the chronological order continues and the editing is smooth. From adolescence to adulthood. The first second of the shot is a group photo between the brothers and sisters. The next second photo turned into two photos of two people who became celebrity actors. In just a few seconds, the director used montage thinking. Make a combo clip that spans several years in a matter of seconds. Through such montage clips, the character's inner emotional changes are shown, and the art of the film is enhanced. 


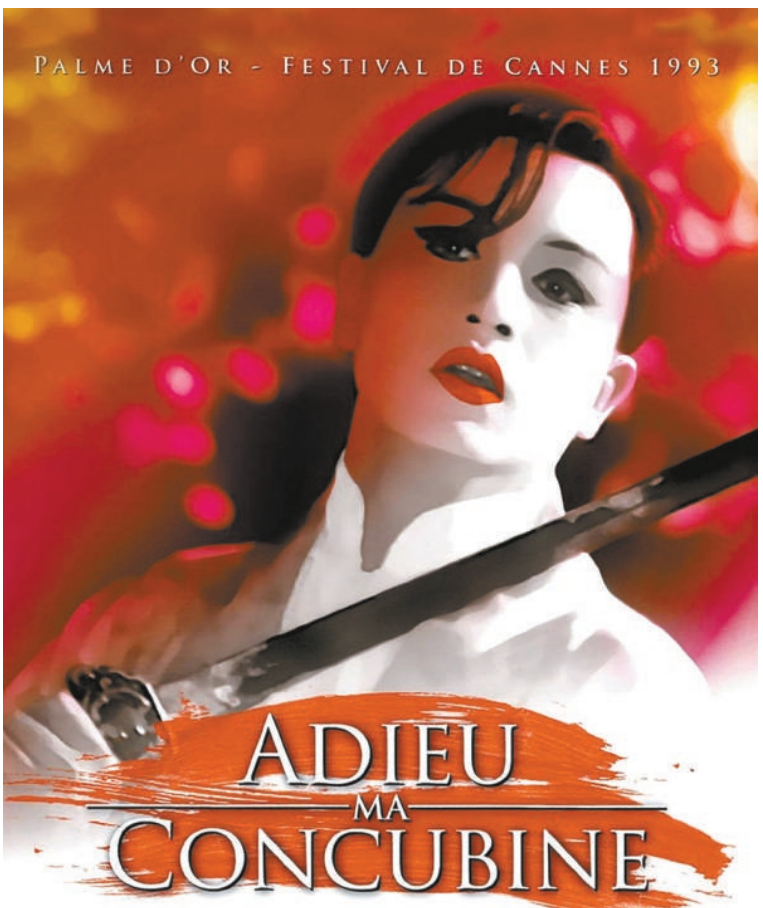

$\mathrm{C} \stackrel{\mathrm{H}}{\mathrm{H}} \stackrel{\mathrm{F}}{\mathrm{N}} \stackrel{\mathrm{L}}{\mathrm{K}} \mathrm{A} \stackrel{\mathrm{D}}{\mathrm{E}} \mathrm{G}$ E

Figure 2. French Poster of the film Farewell My Concubine [4].

\section{THE USE OF MONTAGE IN HAPPY TOGETHER}

Happy together is a Hong Kong gay film directed by Wang Jiawei. The film is mainly a pair of gay lovers between $\mathrm{Li}$ Yaohui and He Baorong. The two went to Argentina. The contradiction between the two is increasing and they are in an emotional crisis. The scene where the two protagonists first met in the bar used a contrasting montage. Using the alternating shots inside and outside the bar, it took a short time to show the different lifestyles of the two people, and laid the foundation for the emotional crisis that occurred after the two went to Argentina after the film ended. Li Yaohui saw He Baorong drunk home in the clip, the lens completely followed the hero shaking, swinging, fully reflects the depressed $\mathrm{Li}$ at that time, difficult to vent the mood, at the same time cannot please He's boring mood. Wang Jiawei's film uses flexible photography techniques, no longer framed film pictures, but flowing space and characters and pictures. The most obvious manifestation of this is that a fragment of lane play that fully reveals the player's perspective, dreamy colors, light lens movement and editing, adding vitality to the entire film. After the montage connection skills, each shot in the Wang Jiawei movie has an explanation or internal connection to the next shot. There are several transition scenes in the movie that are clips of the door, reflecting the scene where two people cross shoulders but no fate meets. In the second half of the movie, the two protagonists embarked on different paths, and the characters that appeared later, Xiao Zhang, the different life trajectories and roads of the three characters, were edited in parallel montages to explain the final direction of the characters. Wang Jiawei film unique editing methods, he always put the time space fragment-like editing, not only to show a story, but also to show a character's inner emotional changes. In this film, the director only used a subjective time narrative, interspersed with the past, the future, now different time and space of what happened, although the real timeline was disrupted by the clip, but the director used a unique approach to the story, using montage to reconstruct the story. Combined with the changes in sound and light, we have created a very good film works.

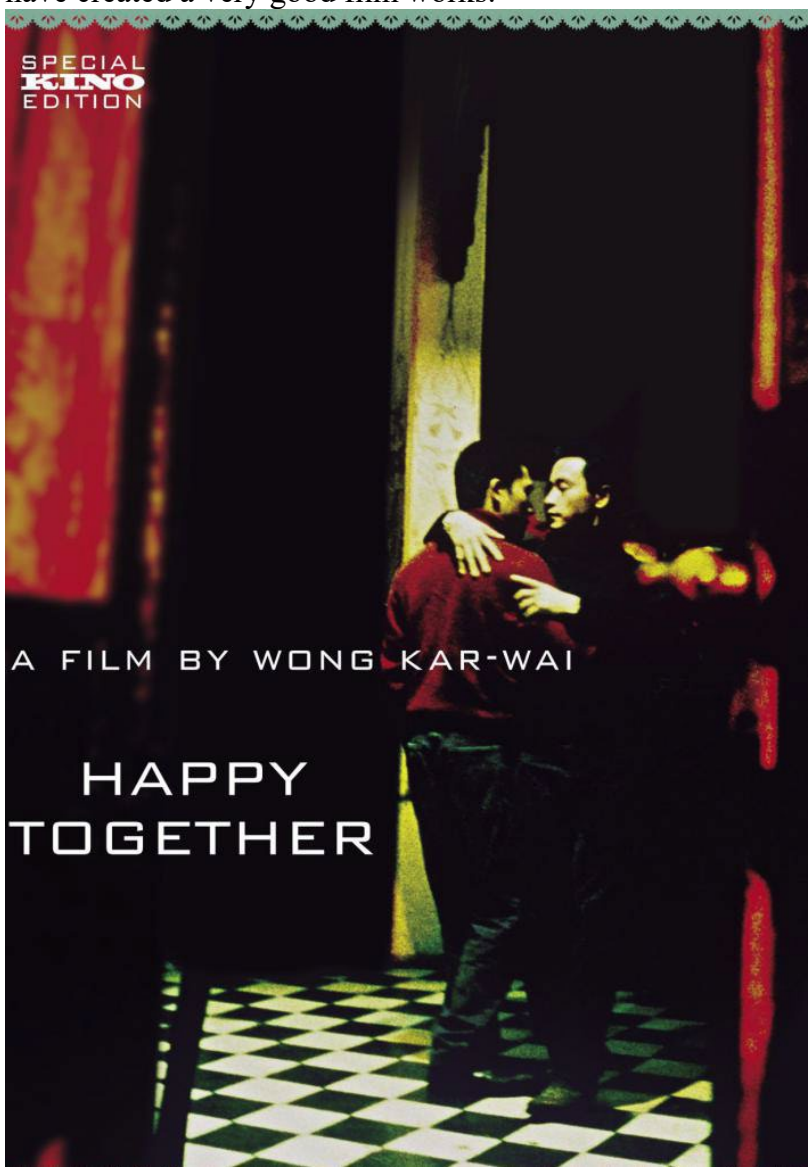

Figure 3. Poster of the film Happy Together [5].

\section{CONCLUSION}

The above-mentioned practical examples show that the editors use the montage method to add charm to the Chinese film. The original material is adjusted, modified, compensated and innovated, making the film more complete and perfect in front of the audience. It can be said that the editing techniques are different, the works displayed will be different, the editing art will be improved, and the continuous development of the Montage School will inevitably promote the continuous development of 
Chinese films. In short, reasonable, logical, and clever editing can increase the charm of film works. Conversely, mistakes, simple, and mediocre editing will reduce or even undermine the charm of the film. The artistic appeal and performance of the film requires editing to enhance the presentation. Without montage, movies can only be attachments to other art. Only after discovering the montage, the film really becomes an independent art, this is no exaggeration.

\section{ACKNOWLEDGMENT}

First and foremost, I would like to show my deepest gratitude to my teachers and professors in my university, who have provided me with valuable guidance in every stage of the writing of this thesis. Further, I would like to thank all my friends and roommates for their encouragement and support. Without all their enlightening instruction and impressive kindness, I could not have completed my thesis.

\section{REFERENCES}

[1] X.Li .The Research on allocation of montage to film production.Zhejiang Normal University master academic papers.2010. pp.17-18.

[2] C.Liu.The use of montage art in films.Movie Literature. 2011, pp. 1-2.

[3] Sina Entertainment. "Crouching Tiger, Hidden Dragon" and "Broken Back Mountain" selected as the best American independent films. 2010.9.10. Retrieved on 2020. 3. 3. Retrieved from: http://ent.chinadaily.com.cn/2010-09/10/content_13695 643.htm

[4] China Social Science Net: Farewell My Concubine French Poster. 2018. 12.13. Retrieved on 2020. 3. 3. Retrieved from: http://ex.cssn.cn/hqxx/xsh/201812/t20181213_4793008. shtml

[5] Jinshichenmo VinX. Happy togeher poster 2016.6.10. Retrieved on 2020.3.3. Retrieved from: https://www.duitang.com/blog/?id=587015993 